\title{
Langerhans cell sarcoma originating from left knee subcutaneous tissue: A case report and literature review
}

\author{
YAONAN ZHANG ${ }^{1}$, ZONGYANG QU $^{2}$ and FANG FANG ${ }^{3}$ \\ Departments of ${ }^{1}$ Orthopedics, ${ }^{2}$ Anesthesiology and ${ }^{3}$ Pathology, Beijing Hospital, Beijing 100730, P.R. China
}

Received December 20, 2014; Accepted January 22, 2016

DOI: $10.3892 / 01.2016 .5194$

\begin{abstract}
Langerhans cell sarcoma (LCS) is a neoplastic proliferation of Langerhans cells with notably malignant cytological features. Reports of LCS are sparsely available in English literature; to the best of our knowledge, only 55 cases have been reported. The present study reports a case of LCS originating from subcutaneous tissue of the left knee in a 75-year-old man. The diagnosis of LCS was supported by the results of magnetic resonance imaging, histological and immunohistochemical studies. The tumor began to metastasize to inguinal lymph nodes and eventually involved multiple organs. Chemotherapy and radiotherapy were administered but were ineffective, and the patient died within 2 years of diagnosis. The present case should aid in expanding the currently available knowledge concerning LCS.
\end{abstract}

\section{Introduction}

The World Health Organization classifies Langerhans cell tumors into two types: Langerhans cell sarcoma (LCS) and Langerhans cell histiocytosis (LCH) (1). LCS is a neoplastic proliferation of Langerhans cells with markedly malignant cytological features, whereas LCH is proliferative disorder of Langerhans cells (1). LCS may occur in individuals of a broad age range, and is highly metastatic (2). The disease may involve multiple organs or tissues (3), including bone, lung, skin, lymph nodes, gallbladder, tonsil and other soft tissues. In the clinic, LCS is an extremely rare disease that is unfamiliar to dermatologists (2). The clinical behavior of the disease is aggressive and the overall survival rate for affected patient's is $<50 \%$ (3). Several therapeutic regimens have been investigated for the treatment of LCS, including surgery, chemotherapy, radiation therapy and combined therapy (3). However, due

Correspondence to: Dr Yaonan Zhang, Department of Orthopedics, Beijing Hospital, 1 Dongdan Dahua Road, Beijing 100730, P.R. China

E-mail: zhangyaonan163@163.com

Key words: Langerhans cell sarcoma, subcutaneous tissue, diagnosis, therapy to the limited number of cases reported in the literature to date, no standard effective therapy has been suggested for the treatment of LCS (3). Among LCS patients, the therapeutic outcomes vary depending on the extent of the disease. In addition, the prognosis of the disease is poor and relapses usually occur within the first 3 years after excision (3).

The current study reports one case of LCS that originated from the subcutaneous tissue of the left knee of a male patient. In addition, all reported cases of LCS available in the English literature are summarized.

\section{Case report}

A 75-year-old male patient was admitted to Beijing Hospital (Beijing, China) on November 4, 2010, complaining of an egg-sized mass located at the medial part of his left knee. The patient reported that the mass had gradually enlarged during the past two months and caused mild-to-moderate pain at night. The pain would somehow be relieved during the daytime and after taking non-steroidal anti-inflammatory drugs. The patient had a medical history that included tonsillectomy 55 years previously, subtotal thyroidectomy 40 years previously (pathology indicated a thyroid adenoma), partial prostatectomy 15 years previously (benign pathology), radical operation for colorectal cancer 5 years previously (pathology indicated intramucosal carcinoma) and a resection of mass of the buttock 4 years previously (pathology indicated an abscess).

Physical examination revealed a firm mass of $\sim 3 \times 3 \mathrm{~cm}$ on the patient's left knee. Inguinal lymph nodes were palpated on both sides and were found to be small, round and soft. X-ray imaging indicated hyperosteogeny in the knee joint and an ultrasound of the mass revealed a low-echo region in the subcutaneous tissue. Magnetic resonance imaging (MRI) revealed a mass measuring $\sim 40 \times 12 \times 15 \mathrm{~mm}$ with a clear boundary in the subcutaneous tissue on the anterior-medial side of the patient's left patella (Fig. 1). The mass exhibited homogeneous signal isointensity relative to that of muscle on T1-weighted imaging (Fig. 1A), and predominantly signal hyperintensity on T2-weighted imaging (Fig. 1B). A number of small patchy hyperintense signals were observed within the mass (Fig. 1B).

The patient received a knee arthroscopic surgery on November 10, 2010. Grossly, a 4x3×2-cm, gray mass was identified, located subcutaneously and with a clear border. No infiltration into the joint space was observed. Thus, the patient underwent a surgical resection of the mass. A 

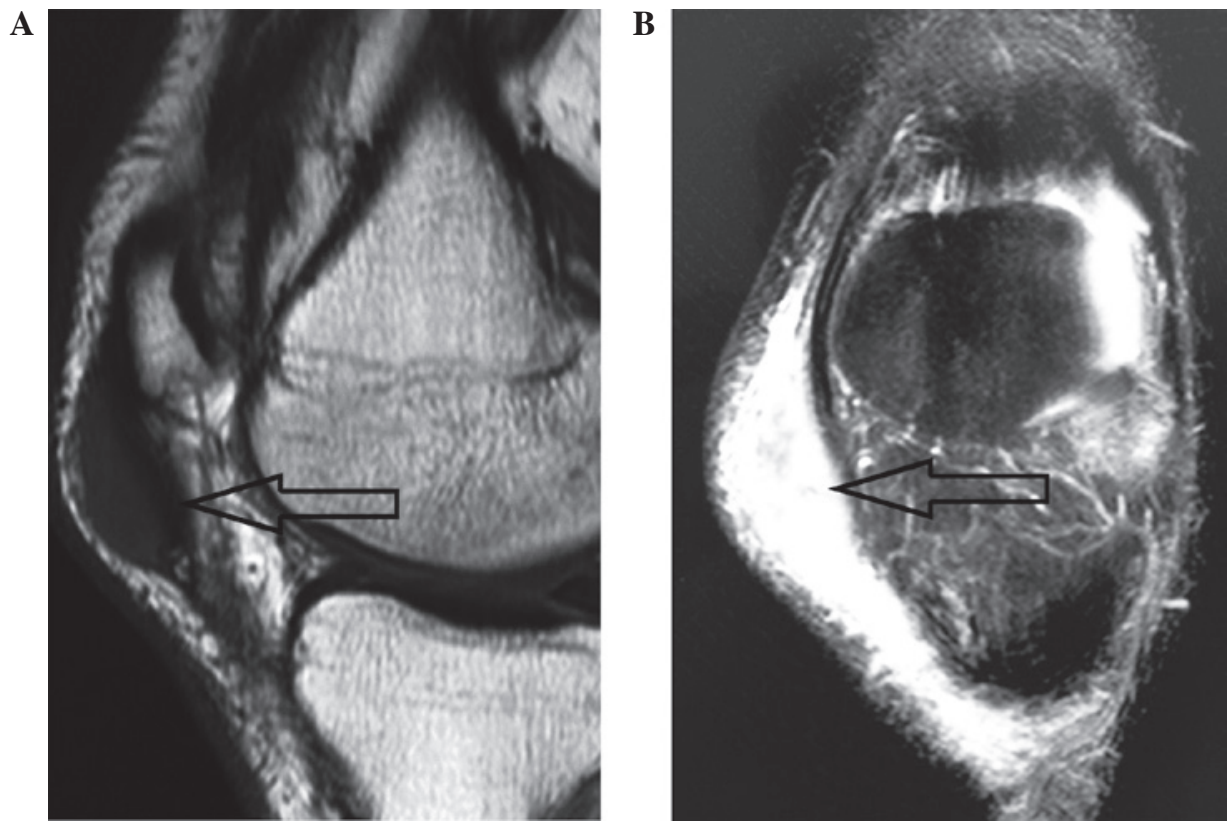

Figure 1. Magnetic resonance images of the patient's left knee. (A) T1-weighted imaging revealed a mass with homogeneous signal isointensity relative to that of muscle. (B) T2-weighted imaging revealed predominantly signal hyperintensity in the mass area. Arrows indicate the mass.

4.8x3.6x1.2-cm specimen was obtained. The cut surface of the resected specimen was gray, soft, and had a pseudo-membrane. Histological examination of the specimen buy hematoxylin and eosin staining indicated an infiltrative tumor mass. The tumor cells were surrounded by abundant lymphocytes, plasma cells and eosinophils (Fig. 2). The neoplastic cells exhibited cytological atypia, hyperchromatic nuclei and prominent nucleoli. Nuclear grooving was also observed in some of the neoplastic cells (Fig. 2). Immunohistochemical stains were positive for cluster of differentiation (CD)1a (+; rabbit monoclonal antibody; catalog no. AC-0078; 1:200 dilution; Baili Biotechnology Co., Ltd., Changhun, China; Fig. 3A), CD68 (+; mouse monoclonal antibody; catalog no. Z-2071; 1:200 dilution; Zeta Corporation, Los Angeles, CA, USA; Fig. 3B), S-100 (++; rabbit polyclonal antibody; catalog no. NCL-L-S100p; 1:150 dilution; Leica Microsystems, Ltd., Milton Keynes, UK; Fig. 3C) and vimentin (+++; mouse monoclonal antibody; catalog no. 202M-96; 1:150 dilution; Cell Marque, Sigma-Aldrich, St. Louis, MO, USA). The tests were negative for desmin (mouse monoclonal antibody; catalog no. 243M-16; 1:100 dilution; Cell Marque, Sigma-Aldrich), CD30 (mouse monoclonal antibody; catalog no. UM800033; 1:200 dilution; Origene Techynologies Inc., Rockville, MD, USA), CD15 (mouse monoclonal antibody; catalog no. CM073C; 1:200 dilution; Biocare Medical LLC, Concord, CA, USA), actin (mouse monoclonal antibody; catalog no. 202M-96; 1:150 dilution; Cell Marque, Sigma-Aldrich), HMB-45 (mouse monoclonal antibody; catalog no. Z-2088; 1:150 dilution; Zeta Co., Ltd.), melan-A (mouse monoclonal antibody; catalog no. Z-2052; 1:200 dilution; Zeta Co., Ltd.) and myoglobin (mouse monoclonal antibody; catalog no. NCL-MYOGLOBIN; 1:150 dilution; Leica Microsystems, Ltd.). The Ki-67 index (mouse monoclonal antibody; catalog no. UM800033; 1:200 dilution; Origene Techynologies Inc.) was $\sim 70 \%$ (Fig. 3D). Taken together, the histomorphological, immunohistochemical and MRI findings supported a diagnosis of LCS.
Following the surgery, local radiotherapy was proposed for the patient. Unfortunately, this planned therapy was abolished as the patient was suffering from septic arthritis and fever. However, a careful plan to follow up this patient was established. At $\sim 6$ months after the first surgery, a positron emission tomography-computed tomography (PET-CT) study of the patient revealed a tumor mass in the left inguinal lymph nodes. Surgical resection of the left inguinal lymph nodes was performed in another hospital, Peking Union Medical College Hospital (Beijing, China), due to practical reasons. LCS metastasis to the inguinal lymph nodes was confirmed by the subsequent pathological findings. Unexpectedly, the patient had developed septic arthritis and fever again. Following postoperative recovery, the patient received four cycles (21 days for one cycle) of chemotherapy with cyclophosphamide (1.4 g on day 1$)$, epirubicin hydrochloride (120 mg on day 1$)$, vindesine (4 mg on day 1 ) and prednisone (100 mg/day on days 1-5) at Peking Union Medical College Hospital.

In January 2012, a follow-up PET-CT scan was performed. A $4.2 \times 3.3 \mathrm{~cm}$ soft tissue mass was detected beside the external iliac with a maximal standardized uptake value $\left(\mathrm{SUV}_{\max }\right)$ of around 12.6. Several small lymph nodes located close to the mass had an $\mathrm{SUV}_{\max }$ of 11.5 . Furthermore, the inguinal lymph nodes in the left groin also had high SUVs of 5.1-7.1. Between February and March 2012, the patient received left groin and lateral pelvis local radiotherapy (total dose, 6,000 cGy; 30 fractions over 47 days) at Peking Union Medical College Hospital. However, the treatment was ineffective, and the LCS was found to have metastasized into multiple organs and tissues (liver, omentum and ascites) 2 months later. The patient succumbed to the disease in November 2012.

\section{Discussion}

LCS is a rare neoplastic proliferation of Langerhans cells with notable malignant cytological features (3). Sparse reports of 


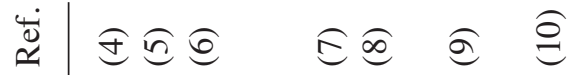

$\widehat{\Xi} \quad \widehat{\mathcal{I}} \widehat{\Xi} \widehat{\Xi} \stackrel{\Xi}{\Xi}$

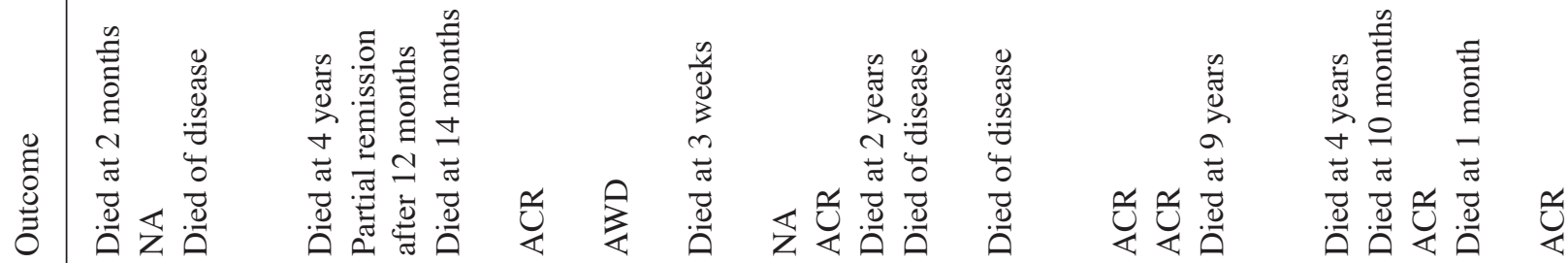

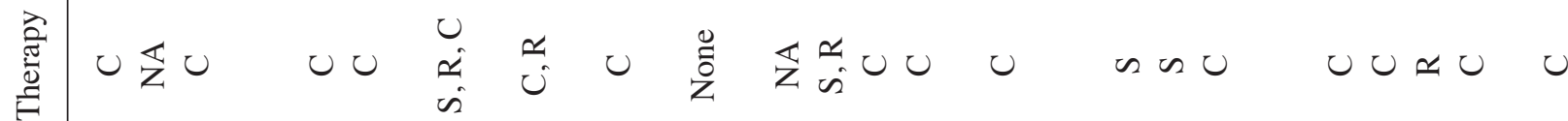

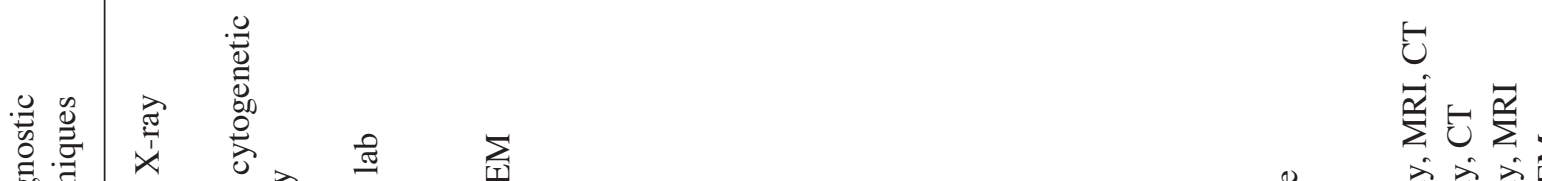

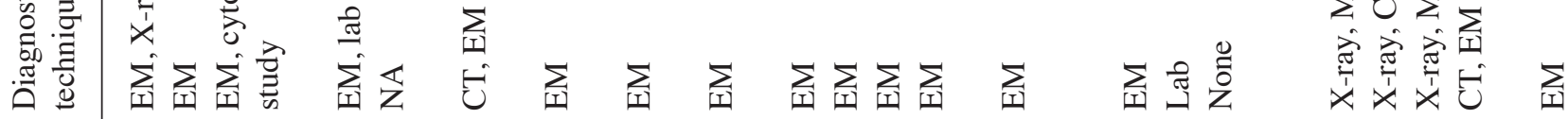

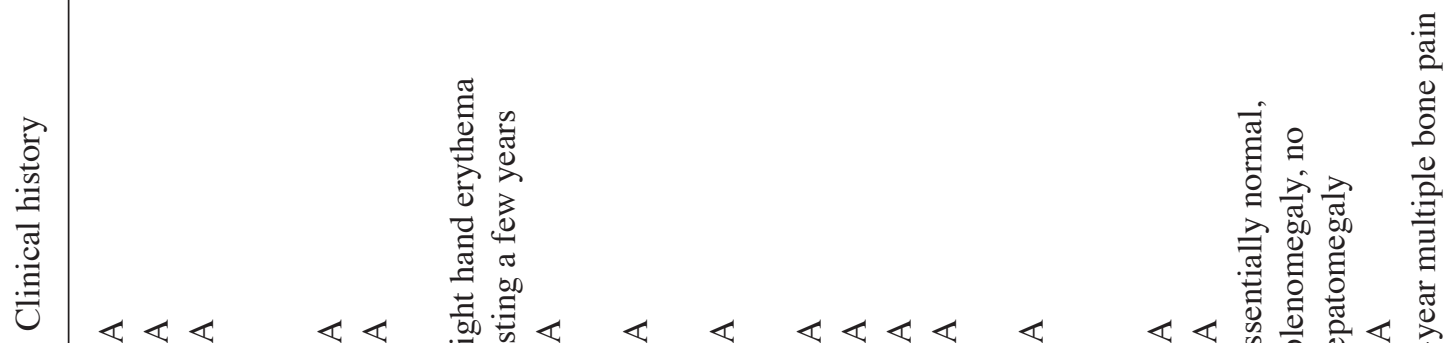

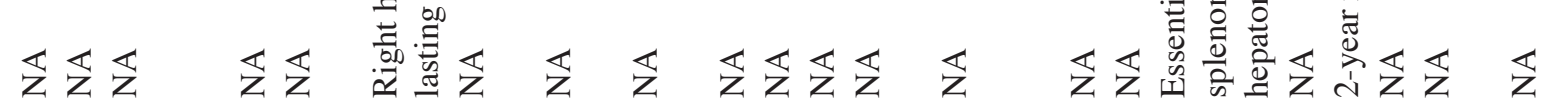
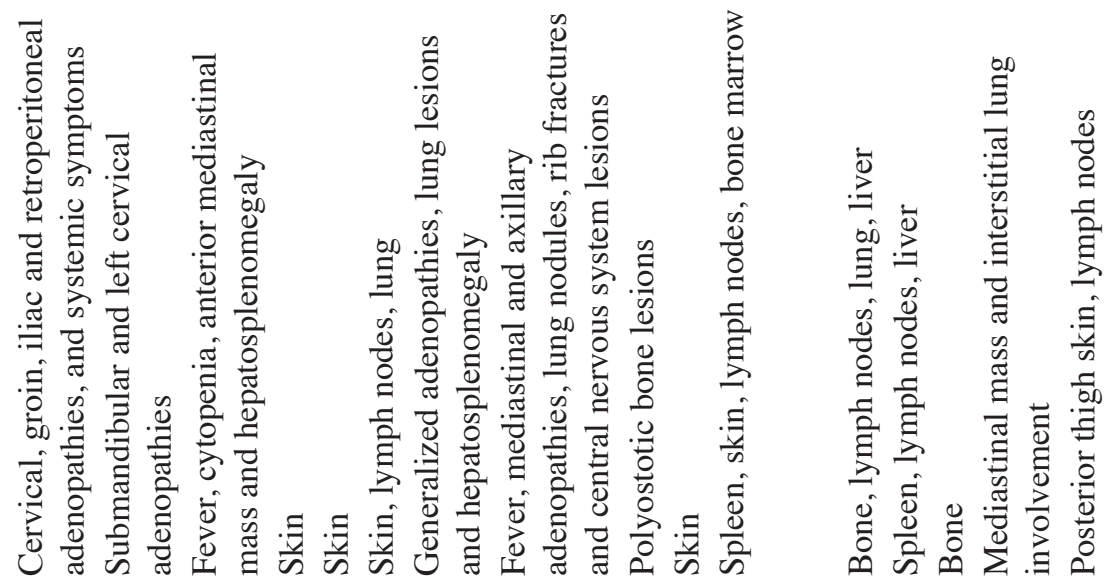

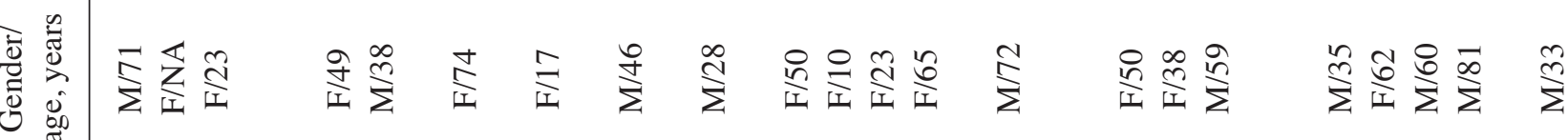

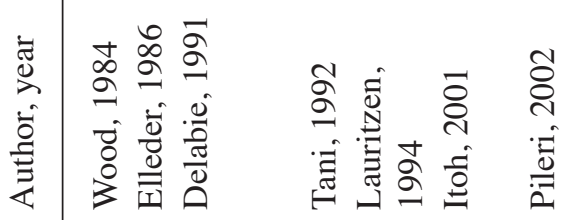

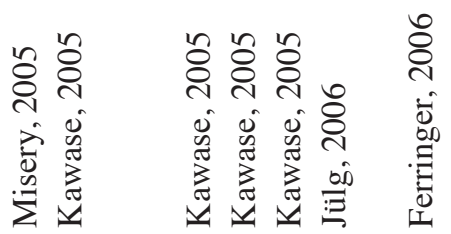

ป

-4m $\tan 0+\infty$ a $0= \pm$

$\pm \quad \because \mathscr{\imath}$

$\stackrel{-\sqrt{4}}{4}$ 


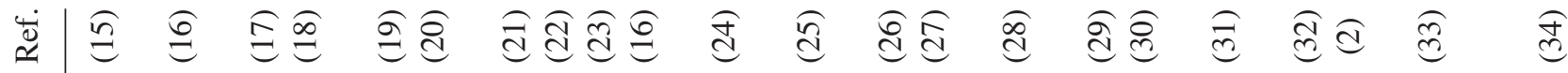

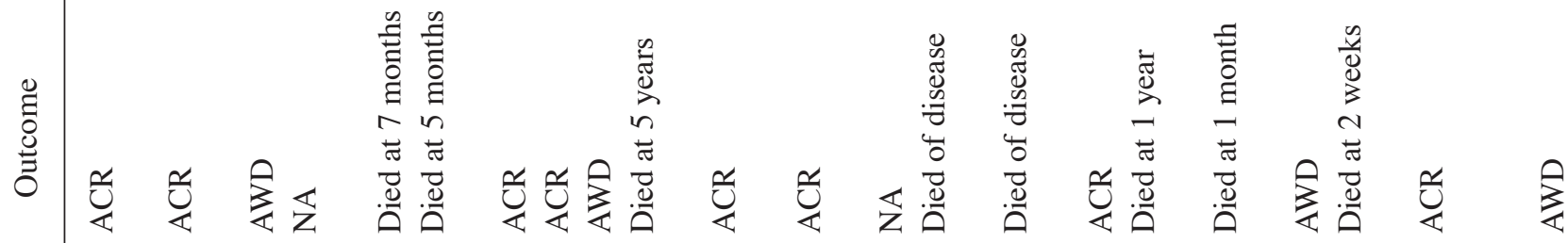

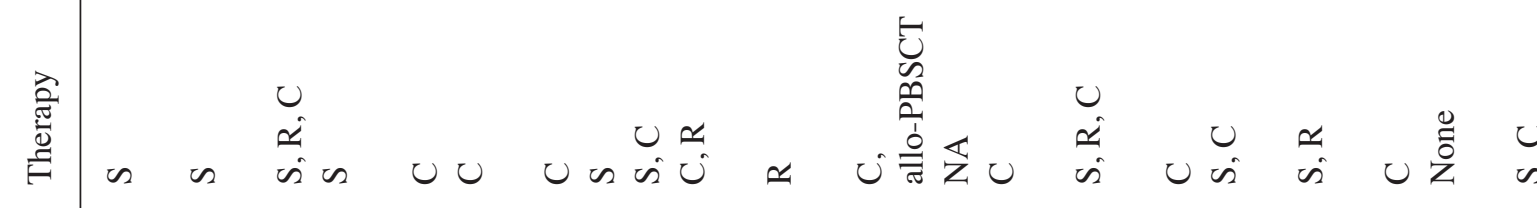

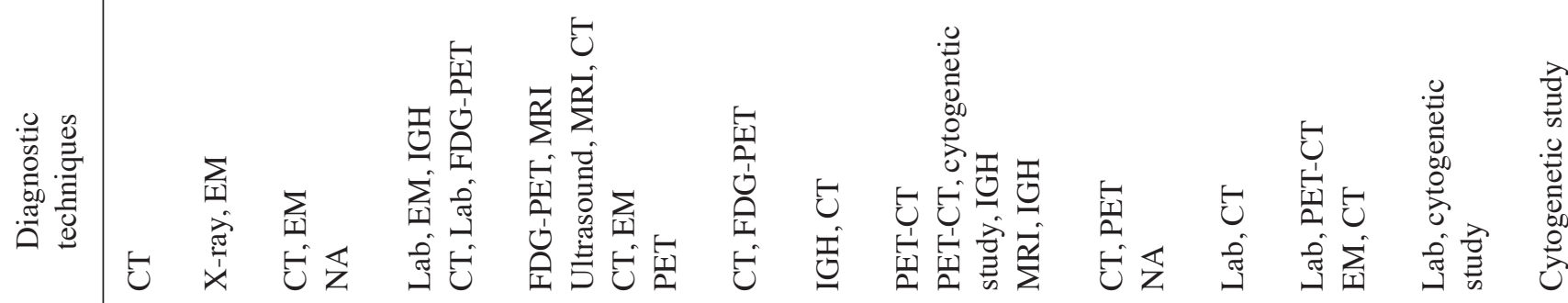

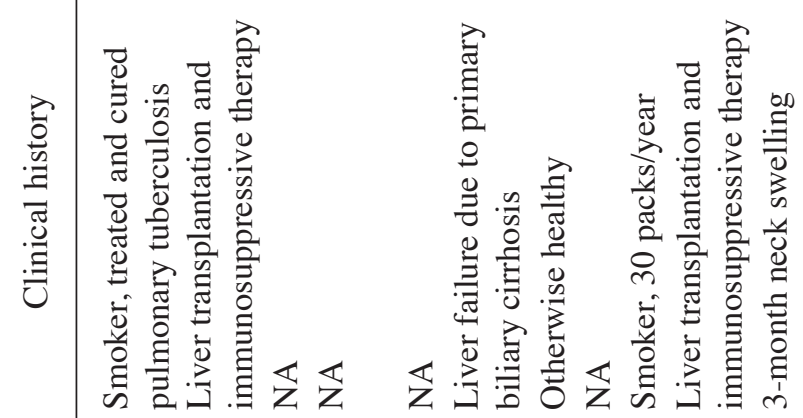
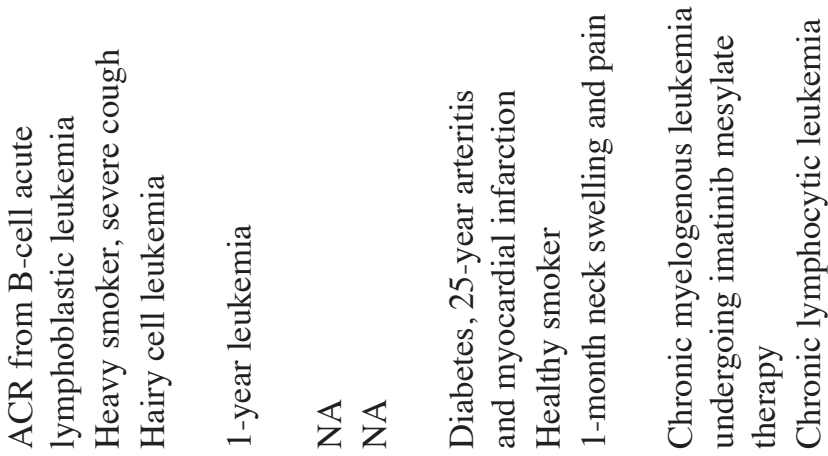

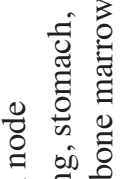

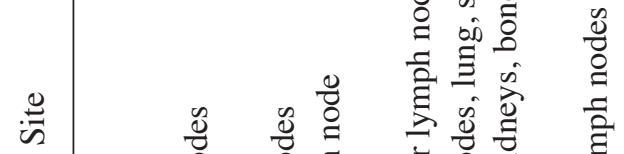

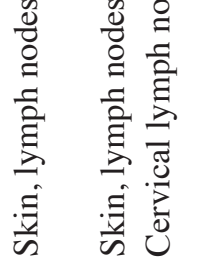

逢

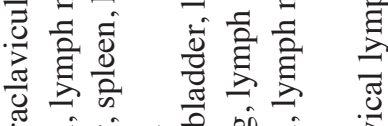

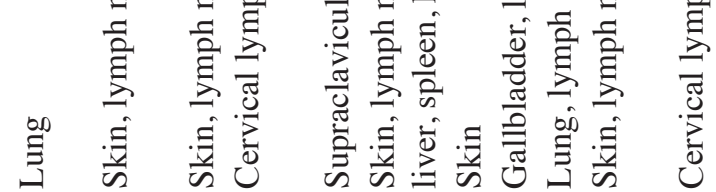

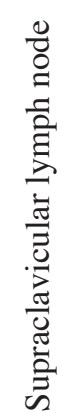

总

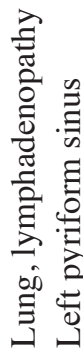

章

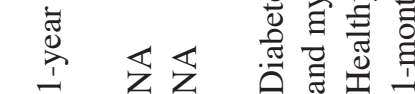

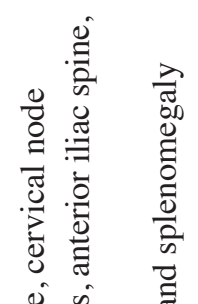

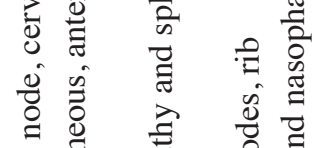

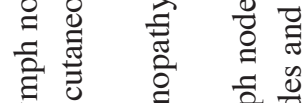

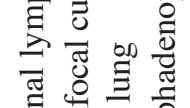

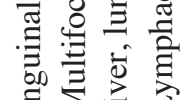

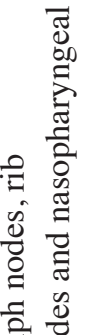

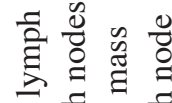

on

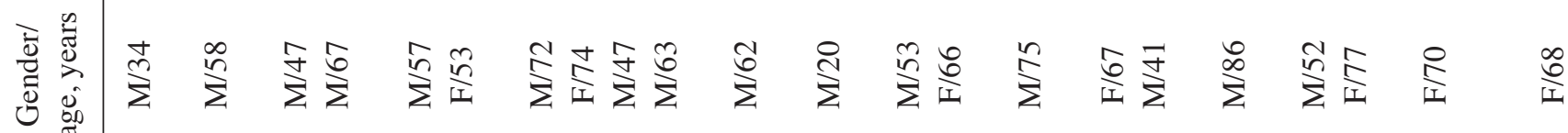

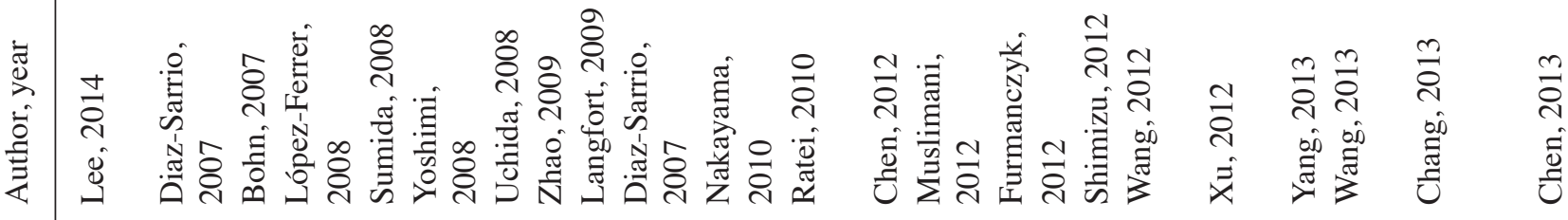




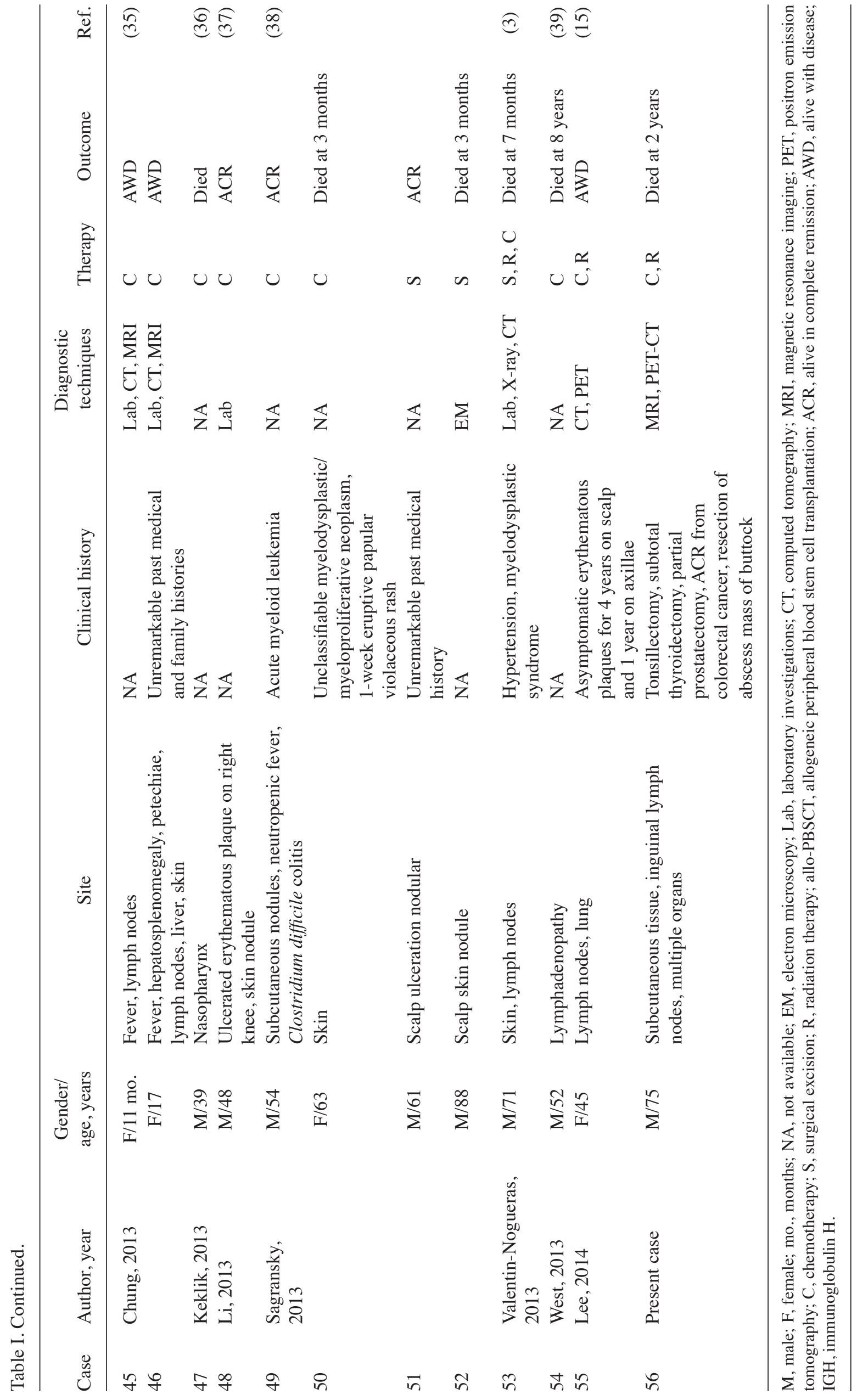



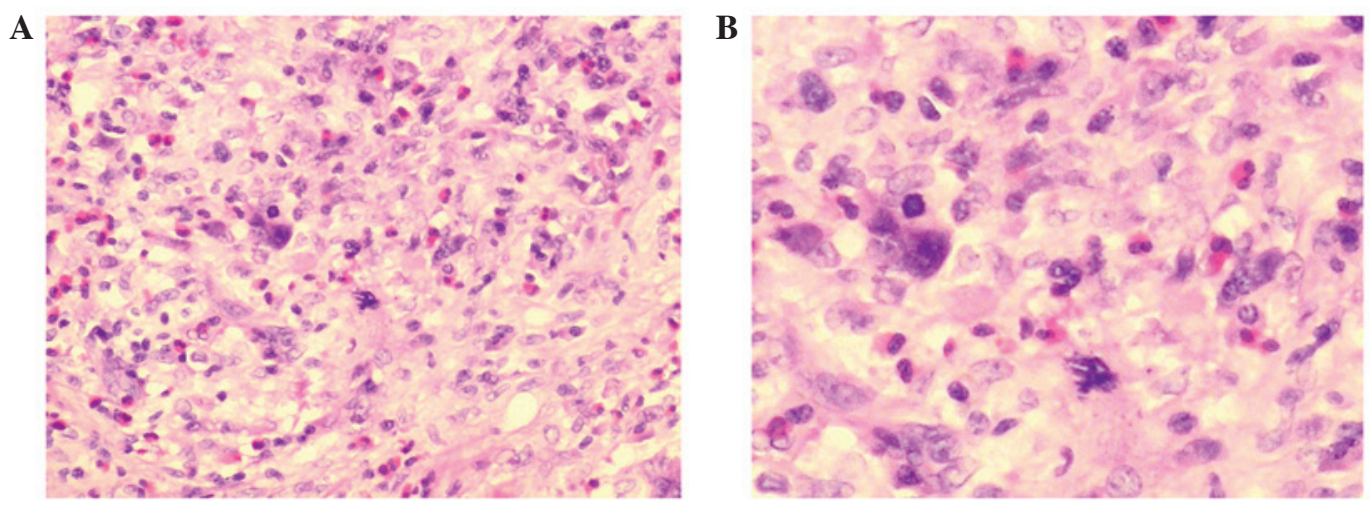

Figure 2. Hematoxylin and eosin staining of the specimen. Original magnifications, (A) x200 and (B) x400.
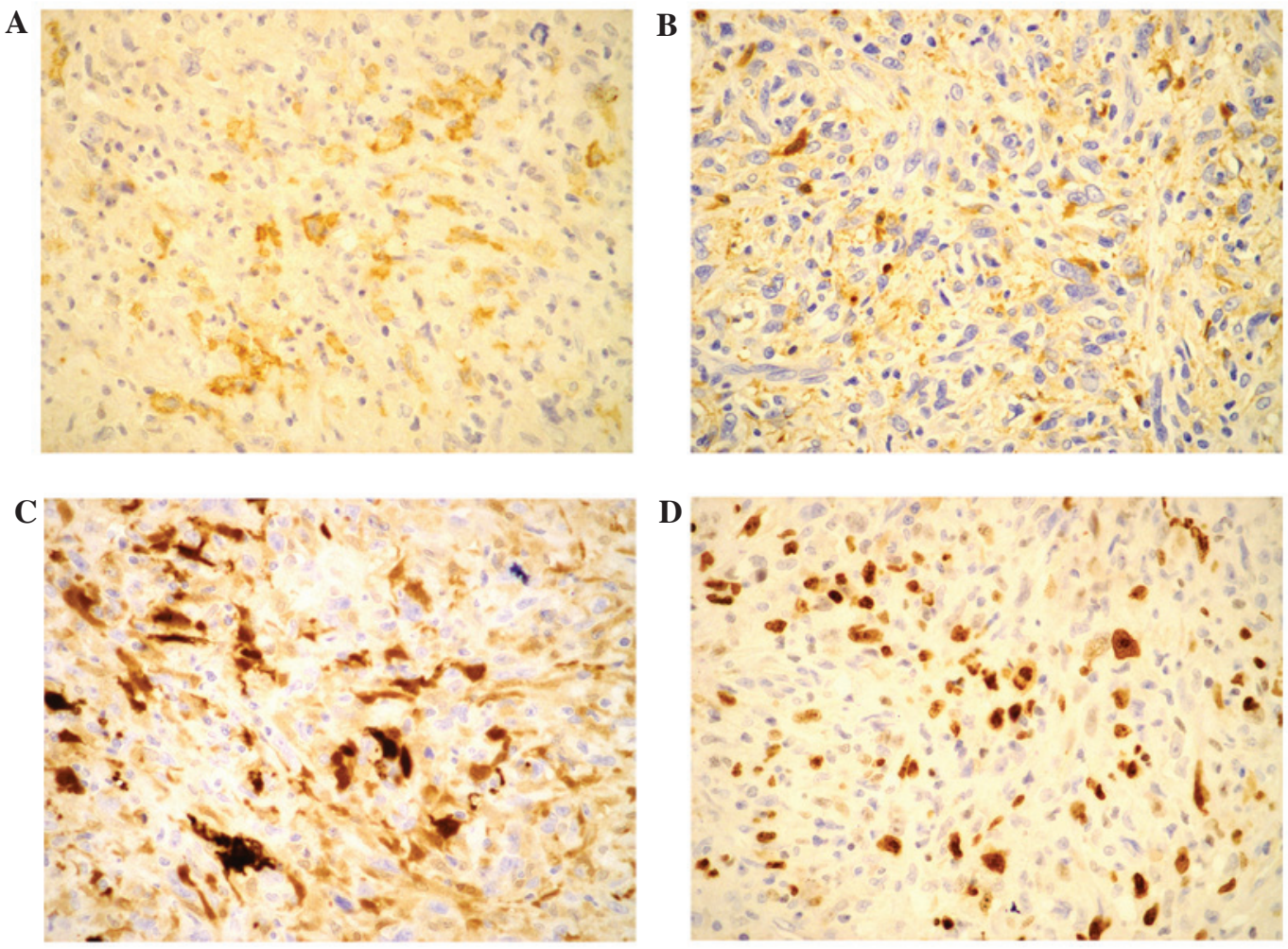

Figure 3. Immunohistochemical studies. Cells were immunopositive for (A) CD1a, (B) CD68 and (C) S-100. (D) The Ki-67 index was 70\%. All images were captured at high magnification (x400). CD, cluster of differentiation.

LCS are available in English literature; to the best of our knowledge, only 55 cases have been reported to date. The available reports are summarized, together with the present case, in Table I [(2) and references therein; (3-39)]. A search of Pubmed was performed to find these reports using the keyword 'Langerhans cell sarcoma' and manual screening was applied. In these cases, the age at diagnosis of LCS ranged from 11 months to 88 years, with a median age of 53 years, and a male:female ratio of 1.4:1. The collective findings also indicate that LCS is extremely aggressive and that it typically metastasizes to multiple organs or tissues.

The differential diagnosis of LCS from LCH may often be challenging due to their histological and immunohistochemical similarities (40). Cytologically, however, LCS exhibits a markedly higher degree of cytological atypia and more frequent mitotic features compared with LCH (10). In the majority of cases, LCS and LCH are immunohistochemically positive for CD1a, S-100 protein and langerin (CD207), while negative for CD21 and CD35; however, LCS commonly has a higher Ki-67 index than LCH (41). Supplementary use of other diagnostic techniques demonstrates great advantages for differentiating between LCS and LCH (35). As shown in Table I, laboratory investigations, electron microscopy, ultrasound, X-ray, CT, MRI, FDG-PET and cytogenetic analysis have been used as accessory techniques in the diagnosis of LCS. In the current case, MRI was utilized during diagnosis and PET-CT was used in follow-up examinations.

Notably, the patient in the present case had an abnormal clinical history compared with other reported cases. The patient had experienced thyroid adenoma, benign prostate 
mass and intramucosal carcinoma. Studies of immunoglobulin heavy chain rearrangement have demonstrated that LCS may not only develop de novo, but may originate from LCH (42) or leukemia (27). Hence, it may be of great importance to analyze the clonal relationship between LCS and other types of tumor cells, such as thyroid adenoma and intramucosal carcinoma as seen in the present case. Unfortunately, such studies were not conducted with the specimen from this patient.

Another phenomenon noted in the present case was that, following the two surgical resections, the patient suffered from septic arthritis and fever. The patient had undergone a resection of a mass of the buttock 4 years prior to his presentation with the left knee mass, and the pathology had indicated an abscess. Whether the septic arthritis was a result of the LCS or was due to the patient's idiosyncrasies was not clear. Nevertheless, close attention must be paid to a patient's clinical history in clinical practice, as such information may aid in the evaluation of the patient's immune surveillance system. The occurrence of LCS has been reported previously in a patient having ongoing immunosuppression therapy following a liver transplant (16).

Due to the rarity of LCS, no standard treatment with good efficacy has been suggested to date (3). Local resection is commonly applied to isolated LCS lesions (Table I). Chemotherapies, such as a modified ESHAP (etoposide, carboplatin, cytarabine, and methylprednisolone) (20) and MAID (mesna, doxorubicin, ifosfamide, dacarbazine) (21) regimens, have been demonstrated to be effective in a proportion of patients. Radiotherapy has also been reported to be effective in certain cases. Complete remission, without signs of recurrence or metastasis for 45 months without adjuvant therapy, was achieved by a total dose of 59.4 Gy radiotherapy to a cervical lymph node LCS patient (25). In the current case, metastasis to inguinal lymph nodes was detected at $\sim 6$ months after the first surgical resection. Furthermore, multiple organs metastasis was detected following four cycles of chemotherapy with adjuvant radiotherapy. Considering the poor outcome and prognosis of LCS, more aggressive and effective standard therapies are urgently required, and a careful follow-up plan is necessary.

In summary, the present study reported a rare case of LCS originating from the subcutaneous tissue of the left knee. The diagnosis, treatment and disease progress of the case were described, which should aid in expanding the currently available knowledge concerning LCS.

\section{Acknowledgements}

The authors acknowledge Dr. Yan Song (Department of Radiology, Beijing Hospital) for providing assistance in the interpretation of the MRI data.

\section{References}

1. Swerdlow SH, Campo E, Harris NL, Jaffe ES, Pieri SA, Stein $\mathrm{H}$, Thiele $\mathrm{J}$ and Vardiman JW (eds): Tumors derived from Langerhans cells. In: World Health Organization Classification of Tumours: Pathology and Genetics of Tumours of Haematopoietic and Lymphoid Tissues. 4th edition. IARC Press, Lyon, France, pp278-289, 2008.

2. Wang YN, Zhou XG and Wang Z: Langerhans cell sarcoma in the cervical lymph node: A case report and literature review. Acta Haematol 129: 114-120, 2013.
3. Valentín-Nogueras SM, Seijo-Montes R, Montalván-Miró E and Sánchez JL: Langerhans cell sarcoma: A case report. J Cutan Pathol 40: 670-675, 2013.

4. Wood C, Wood GS, Deneau DG, Oseroff A, Beckstead JH and Malin J: Malignant histiocytosis X: Report of a rapidly fatal case in an elderly man. Cancer 54: 347-352, 1984.

5. Elleder M, Fakan F and Hula M: Pleiomorphous histiocytic sarcoma arising in a patient with histiocytosis X. Neoplasma 33: 117-128,1986.

6. Delabie J, De Wolf-Peeters C, De Vos R, Vandenberghe E, Kennes K, De Jonge I and Desmet V: True histiocytic neoplasm of Langerhans' cell type. J Pathol 163: 217-223, 1991.

7. Tani M, Ishii N, Kumagai M, Ban M, Sasase A and Mishima Y: Malignant Langerhans cell tumour. Br J Dermatol 126: 398-403, 1992 .

8. Lauritzen AF, Delsol G, Hansen NE, Horn T, Ersbøll J, Hou-Jensen K and Ralfkiaer E: Histiocytic sarcomas and monoblastic leukemias: A clinical, histologic, and immunophenotypical study. Am J Clin Pathol 102: 45-54, 1994.

9. Itoh H, Miyaguni H, Kataoka H, Akiyama Y, Tateyama S, Marutsuka K, Asada Y, Ogata K and Koono M: Primary cutaneous Langerhans cell histiocytosis showing malignant phenotype in an elderly woman: Report of a fatal case. J Cutan Pathol 28: 371-378, 2001.

10. Pileri SA, Grogan TM, Harris NL, Banks P, Campo E, Chan JK, Favera RD, Delsol G, De Wolf-Peeters C, Falini B, et al: Tumours of histiocytes and accessory dendritic cells: An immunohistochemical approach to classification from the international lymphoma study group based on 61 cases. Histopathology 41: $1-29,2002$.

11. Misery L, Godard W, Hamzeh H, Lévigne V, Vincent C, Perrot JL, Gentil-Perret A, Schmitt D and Cambazard F: Malignant Langerhans cell tumor: A case with a favorable outcome associated with the absence of blood dendritic cell proliferation. J Am Acad Dermatol 49: 527-529, 2003.

12. Kawase T, Hamazaki M, Ogura M, Kawase Y, Murayama T, Mori Y, Nagai H, Tateno M, Oyama T, Kamiya Y, et al: CD56/NCAMpositive Langerhans cell sarcoma: A clinicopathologic study of 4 cases. Int J Hematol 81: 323-329, 2005.

13. Jülg B, Weidner S and Mayr D: Pulmonary manifestation of a Langerhans cell sarcoma: Case report and review of the literature. Virchows Arch 448: 369-374, 2006.

14. Ferringer T, Banks PM and Metcalf JS: Langerhans cell sarcoma. Am J Dermatopathol 28: 36-39, 2006.

15. Lee JY, Jung KE, Kim HS, Lee JY, Kim HO and Park YM: Langerhans cell sarcoma: A case report and review of the literature. Int J Dermatol 53: e84-e87, 2014.

16. Diaz-Sarrio C, Salvatella-Danés N, Castro-Forns M and Nadal A: Langerhans cell sarcoma in a patient who underwent transplantation. J Eur Acad Dermatol Venereol 21: 973-976, 2007.

17. Bohn OL, Ruiz-Argüelles G, Navarro L, Saldivar J and Sanchez-Sosa S: Cutaneous Langerhans cell sarcoma: A case report and review of the literature. Int J Hematol 85: 116-120, 2007.

18. López-Ferrer P, Jiménez-Heffernan JA, Alves-Ferreira J, Vicandi B and Viguer JM: Fine needle aspiration cytology of Langerhans cell sarcoma. Cytopathology 19: 59-61, 2008.

19. Sumida K, Yoshidomi Y, Koga H, Kuwahara N, Matsuishi E, Karube K, Oshima K and Gondo H: Leukemic transformation of Langerhans cell sarcoma. Int J Hematol 87: 527-531, 2008.

20. Yoshimi A, Kumano K, Motokura T, Takazawa Y, Oota S, Chiba S, Takahashi T, Fukayama M and Kurokawa M: ESHAP therapy effective in a patient with Langerhans cell sarcoma. Int J Hematol 87: 532-537, 2008.

21. Uchida K, Kobayashi S, Inukai T, Noriki S, Imamura Y, Nakajima H, Yayama T, Orwotho N and Baba H: Langerhans cell sarcoma emanating from the upper arm skin: Successful treatment by MAID regimen. J Orthop Sci 13: 89-93, 2008.

22. Zhao G, Meng L, Wu ZY, Liu Q, Zhang B, Gao RL and Zhang ZQ: Langerhans cell sarcoma involving gallbladder and perineal lymph nodes: A case report. Int J Surg Pathol 17: 347-353, 2009.

23. Langfort R, Radzikowska E, Czarnowska E, Wiatr E, Grajkowska W, Błasińska-Przerwa K, Giedronowicz D and Witkiewicz I: Langerhans cell sarcoma with pulmonary manifestation, mediastinum involvement and bronchoesophageal fistula. A rare location and difficulties in histopathological diagnosis. Pneumonol Alergol Pol 77: 327-334, 2009.

24. Nakayama M, Takahashi K, Hori M, Okumura T, Saito M, Yamakawa M, Tabuchi K and Hara A: Langerhans cell sarcoma of the cervical lymph node: A case report and literature review. Auris Nasus Larynx 37: 750-753, 2010. 
25. Ratei R, Hummel M, Anagnostopoulos I, Jähne D, Arnold R, Dörken B, Mathas S, Benter T, Dudeck O, Ludwig WD and Stein H: Common clonal origin of an acute B-lymphoblastic leukemia and a Langerhans' cell sarcoma: Evidence for hematopoietic plasticity. Haematologica 95: 1461-1466, 2010.

26. Chen YW, Chang CC, Hou PN, Yin SL, Lai YC and Hou MF: The characteristics of FDG PET/CT imaging in pulmonary Langerhans cell sarcoma. Clin Nucl Med 37: 495-497, 2012.

27. Muslimani A, Chisti MM, Blenc AM, Boxwala I, Micale MA and Jaiyesimi I: Langerhans/dendritic cell sarcoma arising from hairy cell leukemia: A rare phenomenon. Ann Hematol 91: 1485-1487, 2012

28. Furmanczyk PS, Lisle AE, Caldwell RB, Kraemer KG, Mercer SE, George E and Argenyi ZB: Langerhans cell sarcoma in a patient with hairy cell leukemia: Common clonal origin indicated by identical immunoglobulin gene rearrangements. J Cutan Pathol 39: 644-650, 2012.

29. Shimizu I, Takeda W, Kirihara T, Sato K, Fujikawa Y, Ueki T, Sumi M, Ueno M, Ichikawa N, Kobayashi H, et al: Long-term remission of Langerhans cell sarcoma by AIM regimen combined with involved-field irradiation. Rinsho Ketsueki 53 1911-1915, 2012 (In Japanese).

30. Wang C, Chen Y, Gao C, Yin J and Li H: Multifocal Langerhans cell sarcoma involving epidermis: A case report and review. Diagn Pathol 7: 99, 2012.

31. Xu Z, Padmore R, Faught C, Duffet L and Burns BF: Langerhans cell sarcoma with an aberrant cytoplasmic CD3 expression. Diagn Pathol 7: 128, 2012.

32. Yang CJ, Lee JY, Wu CC, Yin HL, Lien CT and Liu YC: An unusual pulmonary mass with mediastinal invasion and multiple intrapulmonary nodules in a 52-year-old man. Chest 141 : 253-258, 2012

33. Chang NY, Wang J, Wen MC and Lee FY: Langerhans cell sarcoma in a chronic myelogenous leukemia patient undergoing imatinib mesylate therapy: A case study and review of the literature. Int J Surg Pathol 22: 456-463, 2014.
34. Chen W, Jaffe R, Zhang L, Hill C, Block AM, Sait S, Song B, Liu Y and Cai D: Langerhans cell sarcoma arising from chronic lymphocytic lymphoma/small lymphocytic leukemia: Lineage analysis and BRAF V600E mutation study. N Am J Med Sci 5: 386-391, 2013.

35. Chung WD, Im SA, Chung NG and Park GS: Langerhans cell sarcoma in two young children: Imaging findings on initial presentation and recurrence. Korean J Radiol 14: 520-524, 2013.

36. Keklik M, Sivgin S, Kontas O, Abdulrezzak U, Kaynar L and Cetin M: Langerhans cell sarcoma of the nasopharynx: A rare case. Scott Med J 58: e17-e20, 2013.

37. Li Y, Li B, Tian XY and Li Z: Unusual cutaneous Langerhans cell sarcoma without extracutaneous involvement. Diagn Pathol 8: 20, 2013.

38. Sagransky MJ, Deng AU and Magro CM: Primary cutaneous langerhans cell sarcoma: A report of four cases and review of the literature. Am J Dermatopathol 35: 196-204, 2013.

39. West DS, Dogan A, Quint PS, Tricker-Klar ML, Porcher JC, Ketterling RP, Law ME, McPhail ED, Viswanatha DS, Kurtin PJ, et al: Clonally related follicular lymphomas and Langerhans cell neoplasms: Expanding the spectrum of transdifferentiation. Am J Surg Pathol 37: 978-986, 2013.

40. Zhao G, Luo M, Wu ZY, Liu Q, Zhang B, Gao RL and Zhang ZQ: Langerhans cell sarcoma involving gallbladder and peritoneal lymph nodes: A case report. Int J Surg Pathol 17: 347-353, 2009.

41. Orii T, Takeda H, Kawata S, Maeda K and Yamakawa M: Differential immunophenotypic analysis of dendritic cell tumours. J Clin Pathol 63: 497-503, 2010.

42. Lee JS, Ko GH, Kim HC, Jang IS, Jeon KN and Lee JH: Langerhans cell sarcoma arising from Langerhans cell histiocytosis: A case report. J Korean Med Sci 21: 577-580, 2006. 